\title{
Early Observational Evidence of Polar Motion
}

\author{
Andreas Verdun and Gerhard Beutler \\ Astronomical Institute, University of Bern, Sidlerstrasse 5, CH-3012 \\ Bern, Switzerland
}

\begin{abstract}
Bessel was not able to detect significant latitude variations in his observation series made between May 1820 and June 1821 at Königsberg Observatory. He left the topic until July 22, 1843, when he suspected that the latitude might have changed since 1820. Between March 1842 and April 1843 Peters, one of Bessel's students, performed an observation series of the pole's zenith distance at the Pulkovo Observatory using new observation techniques and reduction methods first developed by Bessel. From this series he deduced a significant value of 0 " $079 \pm 0$ "'017 for the amplitude of polar motion, but he was not able to separate the expected 10 month Eulerian period from an annual signal possibly caused (as he supposed) by seasonal temperature variations. Peters' successors at Pulkovo, Gyldén and Nyrén, continued to observe latitude. Using these observation series Nyrén derived in 1873 significant values for the amplitude of polar motion, but he was not able to determine the phase angles because he assumed the period of polar motion being known. We conclude that Peters probably was the first one to have observed a variation of the latitude, but that he and Nyrén were misled by the Eulerian period when modeling polar motion.
\end{abstract}

\section{Introduction}

The established history of polar motion usually starts with the theoretical foundations layed by (Euler 1765c) and ends with (Küstner 1888), the experimentum crucis $^{1}$, and the empirical evidence given by (Chandler 1891). Not too much attention is paid to the "details" happening between these milestones. We intend to show, instead, that the empirical establishment of polar motion was a continuous process covering almost the entire 19th century. Various analyses prove that polar motion signals are derivable from observation series reaching back to 1846 . It is thus interesting to look for observational evidence for polar motion before the 1880s, when time became mature for the general acceptance of polar motion.

From the historical point of view it is very important to note what is actually meant by the term polar motion. For our purpose it is convenient to distinguish the terms amplitude (i.e., the variation of latitude), phase angle or simply

\footnotetext{
${ }^{1}$ i.e., the inversely phased variation of the latitudes of the International Latitude Service Observatories in the two hemispheres.
} 
phase (i.e., the angle between the axis of maximum moment of inertia and the instant rotational axis and the local meridian of an arbitrary observation site), and period (i.e., the time interval required for the Earth's rotational axis to describe one revolution of the quasi-circular motion on the Earth's surface). The latter term is referred to as the Eulerian period for a rigid Earth, and as the Chandlerian period for an elastic Earth. We will see that the discovery and establishment of these different aspects of polar motion happened at different times.

The empirical discovery and establishment of polar motion is closely connected to the development of and the interaction between theory (modeling), observation methods, and instrumental technique. Around 1840 the theory of polar motion was still far ahead of the development of the instrumental techniques and observation methods to detect this phenomenon. The milestones in the theory of polar motion between 1750 and 1850 are summarized in Table 1.

Major contributions stem from L. Euler (1707 - 1783). He solved the problem of a rotating rigid body between 1750 and 1758 in several steps, e.g., by stating and using his principle of linear momentum, by introducing the Eulerian angles and the principal axes, and by stating and solving the Eulerian equations ${ }^{2}$. Mathematical refinements and general integral solutions were introduced by J.L. de Lagrange $(1736-1813)$ and C. G. J. Jacobi $(1804-1851)$, respectively. L. Poinsot $(1777-1859)$ gave a geometrical interpretation and introduced the names polhode and herpolhode ${ }^{3}$

Meridian and vertical circles played a central role in the discovery of polar motion. The circles were substantially improved during the first half of the 19th century. In the early 1840s the art of constructing and manufacturing precise angle measurement instruments matured. They allowed an observation accuracy of the angular measurements to detect subarcsecond variations of the latitude. The instrumental requirements to measure amplitudes of polar motion of, say, one tenth of an arcsecond, were met by then. The increase of observation accuracy in the 1840 s due to the development of the astronomical circles (and the heliometer) is striking, in particular for the Pulkovo Observatory. This proves the outstanding role that Pulkovo Observatory played in astrometry and polar motion monitoring in the second half of the last century. After its foundation in 1839 the Pulkovo Observatory soon became the most important astronomi-

\footnotetext{
${ }^{2}$ The dates (in Table 1) when Euler presented his memoirs (Euler 1765b, 1767) to the academy are confusingly referenced in (Eneström 1910) and (Winter 1957), p. 167, 244; cf. (Wilson 1987), p. 265. The correct chronological order of Euler's papers is (implicitly) stated in, e.g., (Stäckel 1905), p. 546; and (Jullien 1855), Vol. 2, p. 162. The mistake is easily cleared. The idea of the principal axes was introduced for the first time by J. A. Segner $(1704-1777)$ in (Segner 1755), three years before Euler took it up in his memoir of November 9, 1758.

${ }^{3}$ Poinsot studied the motion of the rotational axis of a freely rotating body and published his solution in (Poinsot 1834), reprinted in the eighth edition of his textbook (Poinsot 1842). An extended version appeared in (Poinsot 1851). C. A. Briot (1817-1882) gave an analytical demonstration of Poinsot's geometrical methods (Briot 1842). Other important contributions to the theory of the rotation of rigid bodies were made, e.g., in different papers written by J.-L. de Lagrange $(1736$ - 1813), P. S. de Laplace $(1749$ - 1827), and S.-D. Poisson (1781 1840 ), but they all excluded the possibility of a variation of the latitude due to geophysical or meteorological reasons; $c f$. (Lagrange 1788), (Laplace 1798, 1799), (Poisson 1809, 1811, 1827, 1833,1838 ), and (Grattan-Guinness 1990), pp. 349-351, 382, $1187-1189,1232-1237$.
} 
Table 1. Milestones of Polar Motion Theory, from 1750 to 1850

\begin{tabular}{|c|c|c|}
\hline Date & Reference & Event \\
\hline Mar 5, 1750 & (Euler 1751) & $\begin{array}{l}\text { Consideration of a variable axis of rotation } \\
\text { due to an external torque. Angle between } \\
\text { axis of figure and axis of rotation "esti- } \\
\text { mated" to be of the order of } 0.022\end{array}$ \\
\hline Sep 3,1750 & (Euler 1752) & $\begin{array}{l}\text { Principle of linear momentum first stated, } \\
\text { rotational motion of a rigid body solved } \\
\text { (in principle) }\end{array}$ \\
\hline Oct 7,1751 & (Euler 1767) & $\begin{array}{l}\text { Introduction of the Eulerian angles. Proof } \\
\text { that there is at least one axis passing } \\
\text { through its centre of gravity in every body } \\
\text { about which it can rotate freely with uni- } \\
\text { form angular velocity }\end{array}$ \\
\hline 1755 & (Segner 1755) & $\begin{array}{l}\text { Introduction of what later Euler called } \\
\text { principal axes }\end{array}$ \\
\hline Jul 6,1758 & (Euler 1765a) & $\begin{array}{l}\text { Proof that there are at least three principal } \\
\text { axes (perpendicular to each other) about } \\
\text { which the centrifugal forces balance }\end{array}$ \\
\hline Nov 9,1758 & (Euler 1765b) & $\begin{array}{l}\text { Integral solution of a rotating rigid body, } \\
\text { motion of rotation about an axis other } \\
\text { than a principal axis, first appearance of } \\
\text { the Eulerian equations, Eulerian or free } \\
\text { nutation, Eulerian period }\end{array}$ \\
\hline Jan 18,1759 & (Euler 1766) & $\begin{array}{l}\text { Analysis of the motion of a three-axial } \\
\text { body with different moments of inertia ro- } \\
\text { tating about an axis not coincident with } \\
\text { one of the principal axes, without and } \\
\text { with external forces }\end{array}$ \\
\hline 1761 & (Euler 1765c) & $\begin{array}{l}\text { Textbook compilation of the achieved re- } \\
\text { sults including minor refinements }\end{array}$ \\
\hline 1788 & (Lagrange 1788) & $\begin{array}{l}\text { Appearance of the Eulerian equations in } \\
\text { their "modern form" }\end{array}$ \\
\hline May 19,1834 & (Poinsot 1834) & $\begin{array}{l}\text { Geometrical interpretation of the cones } \\
\text { described by the rotation axis, introduc- } \\
\text { tion of the terms polhode and herpolhode }\end{array}$ \\
\hline Jul 30,1849 & (Jacobi 1850$)$ & $\begin{array}{l}\text { General integration solution of the Euler } \\
\text { equations using Theta-functions }\end{array}$ \\
\hline
\end{tabular}

cal center world-wide. Its success was based on excellent equipment and on a sound and ambitious scientific program. Pulkovo's leadership in the field of positional astronomy was achieved thanks to the preparatory works performed at Königsberg and Dorpat Observatory as well. Let us refer to the observation techniques and reduction methods developed at Königsberg, Dorpat, and Pulkovo Observatory as the Königsberg-Dorpat-Pulkovo tradition. The astronomers listed in Table 2 have to be associated with this tradition and were deeply involved in 
the history of early polar motion observation ${ }^{4}$. The last three columns indicate the periods of activity of each person at one of the three observatories. Note the "transfer of know how" from Königsberg (Bessel, Peters) and Dorpat (Struve) to the Pulkovo Observatory (the Struve's, Peters, Gyldén, Nyrén).

Table 3 summarizes the milestones in the "early phase" of the empirical discovery of polar motion from 1821 to 1873 . The contributions by Bessel, Peters, and Nyrén are the most important ones. Let us now address the individual activities in Table 3.

Table 2. The Königsberg-Dorpat-Pulkovo tradition

\begin{tabular}{|c|c|c|c|c|c|}
\hline$\overline{\text { Name }}$ & $\overline{\text { Born }}$ & $\overline{\overline{\text { Died }}}$ & $\overline{\text { Königsberg }}$ & $\overline{\overline{\text { Dorpat }}}$ & Pulkovo \\
\hline $\begin{array}{l}\text { F. W. } \\
\text { Bessel }\end{array}$ & $\begin{array}{l}\text { Jul } 22,1784, \\
\text { Minden }\end{array}$ & $\begin{array}{l}\text { Mar } 17,1846, \\
\text { Königsberg }\end{array}$ & $1810-46$ & & \\
\hline $\begin{array}{l}\text { F.G.W. } \\
\text { Struve }\end{array}$ & $\begin{array}{l}\text { Apr } 15,1793, \\
\text { Altona }\end{array}$ & $\begin{array}{l}\text { Nov 23, 1864, } \\
\text { Pulkovo }\end{array}$ & & $\overline{1810-39}$ & $1839-62$ \\
\hline $\begin{array}{l}\text { C. A. F. } \\
\text { Peters }\end{array}$ & $\begin{array}{l}\text { Sep 7, } 1806, \\
\text { Hamburg }\end{array}$ & $\begin{array}{l}\text { May } 8,1880, \\
\text { Kiel }\end{array}$ & $\begin{array}{l}18 ? ?-33 \\
1849-54\end{array}$ & & $1839-49$ \\
\hline $\begin{array}{l}\text { O. W. } \\
\text { Struve }\end{array}$ & $\begin{array}{l}\text { May } 7,1819, \\
\text { Dorpat }\end{array}$ & $\begin{array}{l}\text { Apr 14, 1905, } \\
\text { Karlsruhe }\end{array}$ & & & $1839-89$ \\
\hline $\begin{array}{l}\text { J. A. H. } \\
\text { Gyldén }\end{array}$ & $\begin{array}{l}\text { May 29, 1841, } \\
\text { Helsingfors }\end{array}$ & $\begin{array}{l}\text { Nov } 10,1896, \\
\text { Stockholm }\end{array}$ & & & $1862-71$ \\
\hline $\begin{array}{l}\text { M. } \\
\text { Nyrén }\end{array}$ & $\begin{array}{l}\text { Feb 21, 1837, } \\
\text { Brunskog }\end{array}$ & $\begin{array}{l}\text { Jan } 16,1921, \\
\text { Stockholm }\end{array}$ & & & $1868-08$ \\
\hline
\end{tabular}

\section{First Observational Indications for Variations of Latitude}

Bessel made important contributions to the theory of instruments and of the reduction of observations. His treatment of instrumental errors may be viewed as the most important prerequisite for detecting polar motion. By 1838 Bessel had significantly increased the observational accuracy and considerably improved the reduction methods. Using his Fraunhofer heliometer he was able to measure angles with an accuracy better than a tenth of an arcsecond. In the "race of the detection" of the first stellar parallax Bessel's results turned out to be much better than those of his "rivals" F. G. W. Struve and T. Henderson (17981844). Bessel's observation techniques and reduction methods applied to his Reichenbach and Repsold meridian circles were very promising even to detect polar motion, as well.

Bessel's theoretical considerations on the influence of the variations of the Earth's body on the latitude were motivated by the correspondence with $\mathrm{H}$. W.

\footnotetext{
${ }^{4}$ For detailed biographic information we refer, e.g., to (Bessel 1846), (Peters 1852), (Busch 1856), (Repsold 1919), (Fricke 1970), (Lawrynowicz 1995) or (Verdun 1996) concerning Bessel, to (Winnecke 1881) and (Freiesleben 1974) concerning Peters, to (Batten 1988) and (Sokolovskaya 1974) concerning the Struve family, to (Backlund 1897) concerning Gyldén, and to (Harzer 1923) concerning Nyrén.
} 
Table 3. Milestones of the Empirical Discovery of Polar Motion, from 1821 to 1873

\begin{tabular}{lll}
\hline \hline Date & Reference & Event \\
\hline 1821 & (Bessel 1821) & $\begin{array}{l}\text { First attempt to determine a variation of } \\
\text { the latitude empirically using observations } \\
\text { of the azimuth with respect to a reference } \\
\text { mark. No significant variation detected. }\end{array}$ \\
Jul 22,1843 (Bessel 1844) & $\begin{array}{l}\text { Comparison of the results of the latitude } \\
\text { determinations made in } 1820 \text { and } 1836- \\
\text { 1840. Suspicion that the latitude might } \\
\text { have changed since } 1820 \text { by } 0.155 .\end{array}$
\end{tabular}

Dec 22, 1843 (Peters 1844b) Determination of polar motion using the first homogeneous observation series ever made for this purpose (279 complete Polaris observations during March 11, 1842, until April 30, 1843 (415 days)). Adoption of the Eulerian period. Significant value for the amplitude of polar motion estimated to $+0.079 \pm 0.017$.

Nov 10, 1871 (Nyrén 1872) First attempt to verify Peters'results using Struve's observations made with the Repsold transit circle at Pulkovo between 1840 and 1862.

May 15, 1873 (Nyrén 1873) First reliable evidence for polar motion. Statistically significant values for the amplitudes and the suspected "secular variation" determined using the observation series made by Peters, Gyldén, and Nyrén. Adoption of the Eulerian period. The estimation of the phase angle failed. The importance of long observation time series to determine the period was recognized.

Olbers $(1758-1840)$ between 1814 and $1817^{5}$. He published his results in (Bessel

\footnotetext{
${ }^{5}$ Cf. the letter (No. 219) from Bessel to Olbers dated November 7, 1814, (Erman 1852), Vol. 1, p. $391-392$. Bessel is wondering that nobody before him had studied the rotation of the Earth. This is amazing because copies of (Euler 1765b), (Lagrange 1788), (Laplace 1799), and (Poisson 1811) were available in Bessel's library, cf. (Busch, 1852) p. 42 - 45. Bessel developed his own theory and found that the axis of rotation must not coincide with the axis of maximum moment of inertia, but that it could move with a period of 335 days. Olbers answered on November 19, 1814, cf. letter No. 220, loc. cit., p. 395 . He already knew what Bessel had found, and posed the question about the influence on the Earth's rotational axis caused by mass dislocations on the Earth's surface. Referring again to this topic Olbers stimulated Bessel in a letter dated January 12, 1815, to devote more time and effort to the theory of Earth rotation (cf. letter No. 222, loc. cit., p. $399-400$ ). Bessel claimed to have solved this problem in a letter to Olbers from September 23, 1817, interestingly enough over two and a half years later ( $c f$. letter No. 252, (Erman 1852), Vol. 2, p. 61-64). Starting from the equations for the rotation of a rigid body around the axis of maximum moment of inertia
} 
1818), where he stated the impossibility of a variation of the Earth's axis due to mass dislocations. He pointed out, however, that theoretically polar motion may also occur due to the possibility that the axis of rotation may not coincide with the axis of maximum moment of inertia (which would be the Eulerian or free nutation). It may thus be assumed that Bessel was in doubt whether a categorical rejection of polar motion (in our sense) is justified.

The Reichenbach-Ertel meridian circle was installed in 1819 in the Königsberg Observatory. Using this new instrument, the first transit observations were performed on February 22, 1820, and the first dedicated observation of the latitude were made on March 6, 1820. During the same year a series of test observations was made to test the instrument and for determining instrumental errors and constants. Bessel tried to determine empirically the angle between the rotation axis of the Earth and the axis of maximum moment of inertia. He could not find any (expected) variation of the azimuth with respect to a reference mark and thus concluded that this angle must be very small and thus not significant ${ }^{6}$. Bessel's experiment is probably the first serious attempt in the history of astronomy to determine polar motion in an empirical way. With this negative result the matter was settled for Bessel. He did not touch the issue again before spring 1842 .

In autumn 1841 the new Repsold meridian circle was installed. Bessel tested the instrument carefully until spring 1842. He started to observe Polaris and to determine the graduation errors of the circles. In addition, he tested the performance of the new instrument and determined again the latitude of his observatory with his new meridian circle. The results which Bessel presented in the Astronomische Nachrichten on July 22, 1843, led him to the suspicion that the latitude may have been changed since $1820^{7}$. Obviously Bessel realized that something had happened with the latitude since his last determination in 1820. It was probably this "discovery" that changed his mind concerning the measurability of latitude variations. As opposed to his old convictions based on theoretical considerations of 1817 and on his observation series of 1820 , he no longer excluded the existence of a variation of the latitude. He was convinced that, if the effect really exists, it would be confirmed by observation in the near future. He was also aware of the fact that a (statistically sound) proof would ask for a long and continuous observation series. He must have been aware of the insufficiency of his observations series to confirm the effect. Therefore he tried to observe Polaris whenever possible. In May 1842 he attended the Manchester meeting of the scientific society. He returned on August 25, 1842, and contin-

(which Bessel took from Laplace's Mécanique céleste) influenced by a dislocation of the mass $m^{\prime}$, Bessel derived a value for $m^{\prime}$ of $63 \cdot 10^{15}$ Pounds that would cause a measurable variation of the latitude. He concluded that a variation of the Earth's axis due only to mass dislocations is not possible. In the letter (No. 254), loc. cit., p. $67-68$, dated November 2, 1817, Olbers did not agree with Bessel's categorical rejection of the possibility of a variation of the latitude.

${ }^{6}$ Bessel presented these results in (Bessel 1821), cf. (Engelmann 1875), Vol. 2, p. 42. He determined the "amplitude" of latitude variation to be $0 . " 110 \pm 0.1361$.

'He found the observatory's latitude 0.155 larger than the value determined in 1820 and $0 .{ }^{\prime \prime} 03$ smaller than the one based on the observations made by Busch between 1836 and 1840; cf. (Bessel 1844), col. 22. 
ued his observations immediately. Unfortunately, Bessel's health deteriorated more and more, which forced him to interrupt his observations frequently and sometimes for months. His last observations are dated November 30,1844 . This is why his observation series of Polaris are fragmentary in nature ${ }^{8}$. The observations were concentrated in the months of spring and autumn. Systematic effects thus may not be excluded. In addition, Bessel was not satisfied with the accuracy of the observations made before December $1842^{9}$. His health problems seem to have prevented a complete reduction of his Polaris observations. By the end of 1844 , he was forced to delegate the Polaris observations to his assistant A. L. Busch (1804-1855). Bessel was well aware of the scientific importance of his observations and charged Busch with its reduction and publication. They were issued after Bessel's and Busch's death ${ }^{\mathbf{1 0}}$.

On March 11, 1842, Bessel's former pupil Peters, an astronomer whose achievements are mostly ignored in the history of science ${ }^{11}$, started an observation series at the Pulkovo Observatory with the goal to determine latitude with highest possible accuracy. He presented his first results on December 22, 1842, to the Petersburg Academy of Science. The results were published on March 3, 1844 (Peters 1844b). Most likely Bessel received an offprint or even a preprint of this paper (or a letter reporting first results) from Peters ${ }^{12}$. It is quite clear that Bessel believed he had come close to a discovery of great importance and that he wanted to let the scientific world know about it at the earliest possible moment. This is probably why, in a letter to one of the best known scientists of that time, A. v. Humboldt $(1769-1859)$, dated June 1, 1844, he claimed to have measured a continuous decrease of the latitude of 0.13 between 1842 and $1844^{13}$. It might be that Bessel was stimulated by Humboldt (who was keen to know about the latest "sensations" in science) to pronounce such a vague speculation. Another interpretation is also possible. Bessel wrote his letter to Humboldt, on June 1, 1844 , three months after the publication of Peters' paper. Bessel obviously was close to having evidence for his suspicions against the invariability of the latitude, and Peters' paper clearly supported such an assumption. Unfortunately Bessel was no longer able to improve his own time series. He already had some experiences concerning "fighting for priority". We think of his determination

${ }^{8}$ Bessel's last activities are described in (Busch 1856), p. V - X, LVII - LIX.

${ }^{9}$ Cf. the letter (No. 185) from Bessel to Gauss dated November 24, 1842, (KPAW 1880), p. 550 -551 .

${ }^{10}$ The results were published posthumously in (Busch 1856).

${ }^{11}$ Both a student and a successor of Bessel, Peters sought to ascertain the base of spherical astronomy. Apart from the activities in geodesy, e.g., (Peters 1845a), his investigations concerning nutation (Peters 1844a), the latitude determinations from Polaris observations (Peters 1844b, $1845 \mathrm{~b}$ ), the determination of proper motion of Sirius, and the measurement of parallaxes of fixed stars (Peters 1853a), were his main achievements. He was editor of the Astronomische Nachrichten, of which he edited fifty-eight volumes, from 1855 till the end of his life in 1880.

${ }^{12}$ This assumption is supported by the fact that the Peters' paper is catalogued in Bessel's library, although Bessel had no subscription to the specific journal in which it appeared, cf. (Busch 1852) p. 35 (Entry No. 781).

${ }^{13}$ Cf. (Bruhns 1877) p. 53, (Hagen 1894), and (Przybyllok 1931), col. 365. 
of stellar parallaxes. Those observations were performed in the environment of hard competition with Henderson and Struve. It may be that Bessel was not convinced he would be given priority in the case of parallaxes and wanted to claim priority in the case of latitude variations, as well. He probably hoped to get some reactions about the priority of this empirical discovery from an authority like Humboldt who was very much aware of new developments in science. If he would not be the first, Humboldt might have told him. Priority of discoveries can, from the historical point of view, only be clear in retrospective. It may be that Bessel pointed to this fact by his letter.

Let us point out that both (and even other) interpretations for the "Humboldt-letter" are possible. The issue is not really important. There are, however, two pieces of evidence ruling out Bessel as the "discoverer" of polar motion:

1. Bessel's observations of Polaris are insufficient to detect a variation of the latitude. We do not agree with (Przybyllok 1931) who believes he has shown that Bessel really saw such a variation (and this opinion was shared by others ${ }^{14}$ ). Przybyllok was able to derive a continuous decrease of 0 " 3 only by using additional observations made by Bessel to fill the gaps. Bessel's undersampled Polaris observations could explain the observed effect, although the amplitude then was lower than $0{ }^{\prime \prime} 1^{15}$. It would be of course possible today to determine the variation of the latitude, e.g., using all of Bessel's observations (other than his Polaris observations, i.e., upper and lower culminations of circumpolar stars) and other reduction methods (as Przybyllok had done), but these are procedures which were never used by Bessel, who (on the contrary) seemed to have processed his Polaris observations only. What Przybyllok actually proved is that Bessel might have detected a variation of latitude provided he would have analyzed his entire set of astrometric observations (made for whatever purpose).

2. Bessel's observation series apparently contain signals attributable to polar motion. (Chandler 1902) derived the annual and Chandlerian period from Bessel's observation series made between 1820 and 1827. This does not mean, however, that Bessel could have performed the same analyses. It is likely that Bessel did not believe in a physical variation of the Earth's rotational axis and thus did not look for the Eulerian period ${ }^{16}$. He rather assumed that processes related to mass transfer are responsible for latitude variations. In fact, when raising suspicions against the invariability, he actually thought of a geophysical explanation of the observed phenomenon different from what we understand by polar motion ${ }^{17}$.

\footnotetext{
${ }^{14}$ Cf., e.g., (Hagen 1894) or (Lawrynowicz 1995), p. $146-147$.

${ }^{15}$ Cf. (Chandler 1892), (Ivanof 1894, 1895), (Wanach 1916) p. 207, or (Kimura 1917).

${ }^{16}$ The letter (No. 219) from Bessel to Olbers dated November 7, 1814, (Erman 1852), Vol. 1, p. $391-392$, and the period of 335 days found by Bessel indicate that he was not influenced by the "Eulerian paradigm", i.e., the Eulerian free nutation and the Eulerian period.

${ }^{17}$ This implies the letter from Bessel to Humboldt.
} 


\section{First Observational Evidence for Polar Motion}

In 1840 Peters started working with the great Ertel vertical circle at the Pulkovo Observatory ${ }^{18}$. In order to become acquainted with the instrument and to get an approximate value for the observatory's latitude, he made a series of test observations. The rms error of a single measurement of Polaris' zenith distance was $0^{\prime \prime} 142^{19}$. The instrument was subsequently used for the determination of stellar declinations, of parallaxes, and for the determination of an improved value of the aberration constant. The quality of the first results encouraged Peters to use the instrument with high priority for latitude determinations. In March 1842 Peters was able to model the parameters of the instrument, in particular of the micrometer screws, and to estimate their errors ${ }^{20}$. Meanwhile Struve recognized the problem of dome refraction and attached a sun cover over the observatory ${ }^{21}$. Between March 11, 1842 and April 30, 1843, Peters performed 279 complete observations of Polaris. This included some 10,000 settings and readings of the instrument ${ }^{22}$. These observations may be viewed as the first homogeneous series of this length with the specific goal to monitor the observatory's latitude as a function of time. On December 22, 1843, Peters presented his results to the Petersburg Academy of Sciences. They were subsequently published on March 3, 1844 (Peters 1844b) and reprinted in (Peters, 1845b). Although Peters probably knew about the negative result of the theoretical considerations and of the observations made by Bessel, he refers to (Euler 1765b) and, as opposed to Bessel, was looking for the Eulerian free nutation ${ }^{23}$. Peters modeled the observatory's latitude $\varphi$ by

$$
\varphi=\varphi_{0}+\Delta \varphi+r \cos \left(\xi+432.71^{\circ} \cdot t\right),
$$

where $\varphi_{0}$ is adopted to $59^{\circ} 46^{\prime} 18^{\prime \prime} .736^{\prime \prime}, r$ is the radius of polar motion (amplitude of the variation of latitude), and $\xi$ the phase angle of polar motion (angle between the line defined by the axis of maximum moment of inertia and the instant rotational axis for the epoch 1842.0, and the Pulkovo meridian). The angular velocity of $432.71^{\circ} / y r$ corresponds to an (adopted) Eulerian period of 303.867 mean solar days. He estimated the following values:

$$
\Delta \varphi=+0^{\prime \prime} 019 \pm 0^{\prime \prime} .011 \quad r=+0079 \pm 0 .^{\prime \prime} 017^{\prime \prime} \quad \xi=341.6^{\circ} \pm 14.0^{\circ}
$$

${ }^{18}$ This instrument and its use is described in (Struve 1845) p. 151ff. and (Ambronn 1899), Vol. 2, p. $874-880$.

${ }^{19} \mathrm{Cf}$. (Schumacher 1841), col. 39.

${ }^{20}$ Cf. (Peters 1844b), col. $308-319$.

${ }^{21}$ This problem was already addressed in a letter written by Olbers to Gauss dated December 20, 1823; cf. letter No. 485 in (Schilling 1909), Part. 2, p. $263-265$. Olbers pointed to the problem of the so-called dome refraction. Until 1842 most of the observations were influenced by this effect miming diurnal or seasonal variations in the latitude (Przybyllok 1915). Struve was one of the first who recognized this effect and thus installed a sun cover at his observatory in order to keep the temperature in the dome at a constant level, $c f$. (Nyrén, 1872) p. $2-3$.

${ }^{22}$ Cf. (Struve 1865) p. 37, (Struve 1872), and (Nyrén 1873) p. 3.

${ }^{23}$ Cf. (Peters 1844b), col. 352. 
Two aspects are worthy of note: (1) This kind of modelling polar motion was first used by Peters here, (2) The analysis shows the correct interpretation of the "Eulerian free nutation" and thus reflects Peters' assumption concerning the physical explanation of polar motion. (3) The estimated amplitude of polar motion seems to be significant. The only mistake, as viewed from today, consists of the adoption of the Eulerian period.

Peters recognized that the time interval of his observation series was too short even to separate the expected 10 month Eulerian period from an annual signal possibly caused (as he assumed) by seasonal temperature variations. Peters continued his observations of Polaris and extended his series till November 2,1844 . He performed 92 additional observations. The entire observation series thus contained 371 complete observations covering a time interval of 966 days. Although Peters stayed at Pulkovo until 1849 he did not reduce these new observations ${ }^{24}$. He presented the results of the 1844 paper again in section 87 of his famous researches on the stellar parallaxes published in 1853 (Peters 1853a). It may well be that he first intended to determine the graduation errors of the Ertel vertical circle more carefully. He published the results of these latter investigations even in the same year (Peters 1853b). After returning to Königsberg he could no longer reduce his observations. This and additional data sets were subsequently used by Nyrén.

\section{The Eulerian Paradigm Prevents the Discovery of the "True" Period of Polar Motion in 1873}

On November 10, 1871, Nyrén presented his determination of nutation of the Earth's axis to the Petersburg Academy of Sciences; it was published in 1872 (Nyrén 1872). In this paper Nyrén processed 375 observations of the stars $v$ Ursae Maioris, $\iota$ Draconis, and $o^{2}$ Draconis, made by W. and $O$. Struve between 1840 and 1862, using the Repsold transit circle at the Pulkovo Observatory. Nyrén was obviously proud to say that his determinations were based on the most accurate observation series available at the time allowing him to detect a variation of Pulkovo's latitude. He estimated six parameters: (1) the constant of nutation, (2) the constant of aberration, (3) the parallax in declination, (4) $-\varrho \sin \xi,(5)+\varrho \cos \xi$, and (6) the correction of the adopted mean declination of the star. $\varrho$ is the radius of polar motion (amplitude of the variation of latitude) and $\xi$ is the phase angle of polar motion (angle between the line defined by the axis of maximum moment of inertia and the instant rotational axis for the epoch 1850.0, and the Pulkovo meridian).

Nyrén's analysis, based on a time series of 22 years, failed for two reasons. The first is associated with the model of the periodic variations of the latitude. Nyrén assumed the period to be Eulerian and used Peters' and his own value of $432.0^{\circ} / y r$ and $428.2^{\circ} / y r$ corresponding to 303.87 and 306.81 mean solar days. The first period gave $\xi=252.7^{\circ} \pm 12.1^{\circ}, \varrho=0 . \prime 0452 \pm 0.0^{\prime \prime} 0100$, and the second $\xi=223.8^{\circ} \pm 11.2^{\circ}, \varrho=0.0396 \pm 0.0099$. The second and more important problem was the quality of the observation series. Over $50 \%$ of the observations

\footnotetext{
${ }^{24}$ Peters' observations and its reduction were presented in (Struve 1872) and (Nyrén 1873).
} 
were performed before Struve attached the sun cover on the dome, and thus may be affected by seasonal temperature variations. Nyrén recognized that this data set, although excellent, was not appropriate to detect such small effects. Nevertheless, he stayed optimistic. He performed the same anaysis based on the observation series established by Peters, Gyldén, and himself using the Ertel vertical circle of the Pulkovo Observatory. He knew that the quality of these data sets was even better than the one acquired with the Repsold transit circle.

The first thorough analysis to get evidence for latitude variation was carried out by Nyrén in his famous paper on the determination of Pulkovo's latitude, which he presented to the Academy of Sciences of St. Petersburg on May 15, 1873, and which was published in the same year (Nyrén 1873). This investigation was motivated by his previous attempt to get evidence for polar motion in 1872. He analyzed the observations of Polaris made with the Ertel vertical circle by Peters ( 371 observations covering the time interval from March 11, 1842 till November 2,1844 ), by Gyldén (236 observations covering the time from November 15, 1863 till March 30, 1870), and by himself (155 observations covering the time from June 19, 1871 till May 1, 1873). His analysis was thus based on 762 complete Polaris observations covering a time interval of more than 30 years. After having treated this problem for the second time, Nyrén had no doubts concerning the existence of polar motion. Referring to the results achieved by Peters, he was well aware that he was not the first scientist having seen evidence for polar motion. Using the long, composed time series, Nyrén not only hoped to confirm Peters' results, i.e., by proving a variation of the latitude corresponding to an amplitude of about 0.1 , but he also hoped to confirm the expected Eulerian period of 10 months. He even hoped to find a secular change of the latitude. He also knew that this observation series was qualitatively much better than the one used in (Nyrén 1872). He focused on the detection of a secular variation of the latitude because he did not know exactly the rotational period of polar motion. His model for the determination of the latitude is defined as

$$
\varphi=\varphi_{0}+\varrho \cos \xi \cos \left(428.0^{\circ}\left(T^{\prime}-T\right)\right)-\varrho \sin \xi \sin \left(428.0^{\circ}\left(T^{\prime}-T\right)\right)
$$

where $\varphi_{0}$ is the mean latitude of Pulkovo, $\varrho$ is the radius of polar motion, $\xi$ is the phase angle of polar motion (the angle between the line defined by the axis of maximum moment of inertia and the instant rotational axis, and the meridian of Pulkovo), and $T^{\prime}$ is the epoch of reduction (1842 and 1843 resp. for the observations of Peters, 1866, 1868 and 1873 resp. for the observations of Gyldén and Nyrén). Thus he adopted an average angular velocity of the latitude of $428.9^{\circ} / y r$ corresponding to an Eulerian period of about 307 mean solar days. Similarly to Peters, he solved for 7 parameters: (1) The constant of aberration 20"4451, (2) Parallax of Polaris in declination. (3) $+\varrho \sin \xi$, (4) $\varrho \cos \xi$, (5) Correction of the adopted mean declination of Polaris, (6) Correction of the latitude $59^{\circ} 46^{\prime} 18^{\prime \prime} 67$, and (7) Corrections of the adopted values for precession and proper motion in declination of Polaris. He found the following results for the "secular variation" of the latitude (Table 4).

Nyrén was convinced that this secular variation was real and significant. What he had disregarded is a possible aliasing effect due to the sampling of the periodically varying values for the latitude. For the periodic variation of the latitude he found the following values (Table 5). 
Table 4. Nyrén's results for the "secular variation" of the latitude

\begin{tabular}{ll}
\hline \hline Observation series & Resulting latitude \\
\hline Peters' observations for the epoch 1843: & $\varphi=59^{\circ} 46^{\prime} 18^{\prime \prime} \cdot 727 \pm 0.013$ \\
Gyldén's observations for the epoch 1866: & $\varphi=59^{\circ} 46^{\prime} 18^{\prime \prime} .654 \pm 0.0^{\prime \prime} 014$ \\
Nyrén's observations for the epoch 1872.5: & $\varphi=59^{\circ} 46^{\prime} 18^{\prime \prime} .501 \pm 0.0^{\prime \prime} 014$ \\
\hline
\end{tabular}

Table 5. Nyrén's results for the periodic variation of the latitude

\begin{tabular}{lll}
\hline \hline Observation series & Resulting phase angle & Resulting amplitude \\
\hline Peters'series for epoch 1843: & $\xi=52.7^{\circ} \pm 6.2^{\circ}$ & $\varrho=0^{\prime \prime} 101 \pm 0.014$ \\
Gyldén's series for epoch 1868: & $\xi=290.6^{\circ} \pm 8.7^{\circ}$ & $\varrho=0^{\prime \prime} 125 \pm 00^{\prime \prime} 017$ \\
Nyrén's series for epoch 1868: & $\xi=85.1^{\circ} \pm 19.3^{\circ}$ & $\varrho=0 !^{\prime \prime} 058 \pm 00^{\prime \prime} 015$ \\
\hline
\end{tabular}

Nyrén was obviously disturbed with these results. On one hand the values for the amplitudes of polar motion seemed to be very accurate and significant. On the other hand the phase angles of polar motion, reduced to the same epoch of 1868 differed considerably (Table 6).

Table 6. Nyrén's resulting phase angles for two adopted periods

\begin{tabular}{lrr}
\hline \hline Adopted period: & $428.9^{\circ} / y r$ & $430.3^{\circ} / y r$ \\
Peters' observations reduced to epoch 1868 & $335.2^{\circ}$ & $10.2^{\circ}$ \\
Gyldén's observations reduced to epoch 1868 & $290.6^{\circ}$ & $293.6^{\circ}$ \\
Nyrén's observations reduced to epoch 1868 & $85.1^{\circ}$ & $79.1^{\circ}$ \\
\hline
\end{tabular}

Nyrén was not able to explain these results. He was disappointed but also convinced that permanent observation series could help to understand the phenomenon of polar motion. He thus formulated what 20 years later became the general program for the International Latitude Service (ILS): the continuous monitoring of polar motion to detect its periods and amplitudes. He could not know that his observation series and results actually were excellent, but that his model was based on one false assumption (namely, the misleading Eulerian period). He should (and could) have introduced the period(s) as a parameter, as well. Nyrén was completely right, on the other hand, that long, uninterrupted time series were required to reveal the secrets of Earth rotation. This seems to be an "external truth."

\section{Conclusions}

First suspicions against the invariability of the latitude arose in the early 1840 s, when Bessel and Peters started with their dedicated observation campaigns. Starting in 1842 , the first homogeneous observation series of high quality were performed at Pulkovo Observatory with the goal to determine the latitude. A first significant value for the amplitude of polar motion was determined by Peters in 1843. In 1873 Nyrén confirmed Peters' results and estimated a "secular variation" of polar motion using Peters', Gyldén's, and his own observation series. The Eulerian paradigm, i.e., the Eulerian period of the free nutation, prevented 
Nyrén from detecting the "true" period already in 1873. It is thus an anachronistic simplification to attribute the "empirical discovery" of polar motion to Küstner only. If the discovery of polar motion is considered as the discovery of its amplitude or the variation of the latitude it has to be credited to Gyldén and Nyrén or even to Peters. If the discovery of polar motion is associated with the discovery of its correct description, including its "true" period(s), then it should be attributed to Chandler. We thus conclude that the empirical establishment of polar motion was a continuous process that stretched over almost the entire 19 th century.

\section{References}

Ambronn, L., 1899, Handbuch der astronomischen Instrumentenkunde, 2 Vols., Berlin, Springer.

Backlund, O., 1897, Vierteljahrsschr. d. Astron. Ges., 32, 8-23.

Batten, A. H., 1988, Resolute and undertaking characters: the lives of Wilhelm and Otto Struve, Dordrecht, Reidel, (ASSL, 139).

Bessel, F. W., 1818, Z. f. Astron., V, 25, (Engelmann, 1875, 3, 304-306).

Bessel, F. W., 1821, Astron. Beob. a. d. Königl. Univ.-Sternw. Königsberg, 6, III, (Engelmann, 1875, 2, 34-43).

Bessel, F. W. 1844, AN, 21, 1-32.

Bessel, F. W., 1846, Kurze Erinnerungen an Momente meines Lebens, In: Erman, 1852, 1, IX - XXX; (Engelmann, 1875, 1, XI-XXXI).

Briot, C., 1842, J. Math. pures et appl., 7, 70-84.

Bruhns, K., 1877, Briefwechsel zwischen A. v. Humboldt und Gauss, Leipzig.

Busch, A. L., 1852, Systematisches Verzeichniss der in der Bibliothek der Königl. Universitäts-Sternwarte zu Königsberg enthaltenen Bücher, Astron. Beob. a. d. Königl. Univ.-Sternw. Königsberg, 25.

Busch, A. L. 1856, Astron. Beob. a. d. Königl. Univ.-Sternw. Königsberg, 27.

Chandler, S. C., 1891, AJ, 11, 59-61.

Chandler, S. C., 1892, AJ, 12, 97-101.

Chandler, S. C., 1902, $A J$, 22, 89-92.

Eneström, G., 1910, Verzeichnis der Schriften Leonhard Eulers, Jahresber. DMV, Erg.-Bd. IV, Leipzig, Teubner.

Engelmann, R. (ed.), 1875, Abhandlungen von Friedrich Wilhelm Bessel, 3 Vols., Leipzig, Engelmann 1875-76.

Erman, A. (ed.), 1852, Briefwechsel zwischen W. Olbers und F. W. Bessel, 2 Vols., Leipzig, Avenarius \& Mendelssohn.

Euler, L., 1751, Mém. Acad. Sci. Berlin, 5 (1749), 289-325.

Euler, L. 1752, Mém. Acad. Sci. Berlin, 6 (1750), 185-217.

Euler, L. 1765a, Mém. Acad. Sci. Berlin, 14 (1758), 131-153.

Euler, L. 1765b, Mém. Acad. Sci. Berlin, 14 (1758), 154-193.

Euler, L. 1765 c, Theoria motus corporum solidorum seu rigidorum, Rostochii et Gryphiswaldiae, A. F. Röse MDCCLXV. 
Euler, L. 1766, Mém. Acad. Sci. Berlin, 15 (1759), 265-309.

Euler, L. 1767, Mém. Acad. Sci. Berlin, 16 (1760), 176-227.

Freiesleben, H. C. 1974, In: Gillispie (1970), 10, 542.

Fricke, W. 1970, In: Gillispie (1970), 2, 97-102.

Gillispie, C. C. (ed.) 1970, Dictionary of scientific biography, 16 Vols., New York, Scribner 1970-80.

Grattan-Guinness, I. 1990, Convolutions in French Mathematics, 1800 - 1840, 3 Vols., Basel, Birkhäuser, (Science Networks, 3).

Hagen, J. G. 1894, AN, 136, 207-208.

Harzer, P. 1923, Vierteljahrsschr. d. Astron. Ges., 58, 50-73.

Ivanof, A. 1894, $A J, 14,180-183$.

Ivanof, A. 1895, Bull. astron., 2, 106-111.

Jacobi, C. G. J. 1850, J. f. d. reine u. angew. Math., 39, 293-350.

Jullien, P. M. 1855, Problèmes de mécanique rationelle, 2 Vols., Paris, MalletBachelier.

Kimura, H. 1917, MNRAS, 78, 163-167.

Klein, F. et al. 1901, Encycl. Math. Wiss., IV/6, T. 1, Leipzig, Teubner 19011908 .

KPAW 1880, Briefwechsel zwischen Gauss und Bessel. Hrsg. auf Veranl. d. Königl. Preuss. Akad. d. Wiss., Leipzig, Engelmann.

Küstner, F. 1888, Neue Methode zur Bestimmung der Aberrations-Constante nebst Untersuchungen über die Veränderlichkeit der Polhöhe, Berlin, Schade.

Lagrange, J.-L. 1788, Méchanique analitique, Paris, Desaint.

Laplace, P. S. 1798, Mém. Classe Inst. France, (1795-96), 301-376.

Laplace, P. S. 1799, Traité de mécanique céleste, 5 Vols., Paris, Bachelier/Duprat 1799-1829.

Lawrynowicz, K. 1995, Friedrich Wilhelm Bessel, 1784-1846, Basel, Birkhäuser, (Vita Mathematica, 9).

Nyrén, M. 1872, Mém. Acad. Imp. Sci. St.-Pétersb., VII, 19 (2), 1-64.

Nyrén, M. 1873, Mém. Acad. Imp. Sci. St.-Pétersb., VII, 19 (10), 1-40.

Peters, C. A. F. 1844a, Mém. Acad. Imp. Sci. St.-Pétersb., VI, 3, 125-227.

Peters, C. A. F. 1844b, Bull. Classe Phys.-Math. Acad. Imp. Sci. St.-Pétersb., 2, 305-352.

Peters, C. A. F. 1845a, $A N$, 22, 33-42.

Peters, C. A. F. 1845b, AN, 22, 71-80, 81-96, 103-110, 119-128.

Peters, C. A. F. 1852, Uebersicht der Leistungen Bessel's in der Stellar-Astronomie und in der Theorie der astronomischen Instrumente. Vortr. am 12. Nov. 1849 in der physik.-ökon. Ges. Königsberg, (Königsb. naturwiss. Unterhalt., II, 101-140).

Peters, C. A. F. 1853a, Mém. Acad. Imp. Sci. St.-Pétersb., VI, 5, 1-180.

Peters, C. A. F. 1853b, Mém. Acad. Imp. Sci. St.-Pétersb., VI, 5, 181-201.

Poinsot, L. 1834, Théorie nouvelle de la rotation des corps, Paris, Bachelier.

Poinsot, L. 1842, Eléments de statique, 8. ed., Paris, Bachelier, 485-526. 
Poinsot, L. 1851, J. Math. pures et appl., 16, 9-129, 289-336.

Poisson, S.-D. 1809, J. Ecole Polytechn., (1)8, 198-218.

Poisson, S.-D. 1811, Traité de mécanique, 2 Vols., Paris, Courcier.

Poisson, S.-D. 1827, Mém. Acad. Sci. Paris, 7, 199-265.

Poisson, S.-D. 1833, Traité de mécanique. 2 Vols, 2. éd., Paris, Bachelier.

Poisson, S.-D. 1838, Mém. Acad. Sci. Paris, 14, 275-432.

Przybyllok, E. 1915, $A N$, 201, 209-218.

Przybyllok, E. 1931, AN, 242, 365-368.

Repsold, J. A. 1919, $A N, \mathbf{2 1 0}, 161-214$.

Schilling, C. (ed.) 1900, Wilhelm Olbers - Sein Leben und seine Werke, 2, Berlin, Springer.

Schumacher, H. C. 1841, AN, 18, 33-48.

Segner, J. A. 1755, Specimen theoriae turbinum, Halle.

Sokolovskaya, Z. K. 1976, In: Gillispie (1970), 13, 108-121.

Stäckel, P. 1905, In: Klein, F. et al. (1901), 435-691.

Struve, O. 1865, Übersicht der Thätigkeit der Nicolai-Hauptsternwarte während der ersten 25 Jahre ihres Bestehens, St. Petersburg, Kaiserl. Akad. Wiss.

Struve, O. 1872, Observations de Poulkova, IV, St.- Pétersb., Acad. Imp. Sci.

Struve, F. G. W. 1845, Description de l'Observatoire astronomique central de Poulkova, St.-Pétersb., Acad. Imp. des Sci.

Verdun, A. 1996, ORION, 273, 97-102.

Wanach, B. 1916, Resultate des Internationalen Breitendienstes, 5, Berlin, Reimer.

Wilson, C. 1987, Arch. Hist. Ex. Sci., 37, 233-273.

Winnecke, A. 1881, Vierteljahrsschr. d. Astron. Ges., 16, 5-8.

Winter, E. 1957, Die Registres der Berliner Akademie der Wissenschaften, 17461766, Berlin, Akademie-Verlag. 


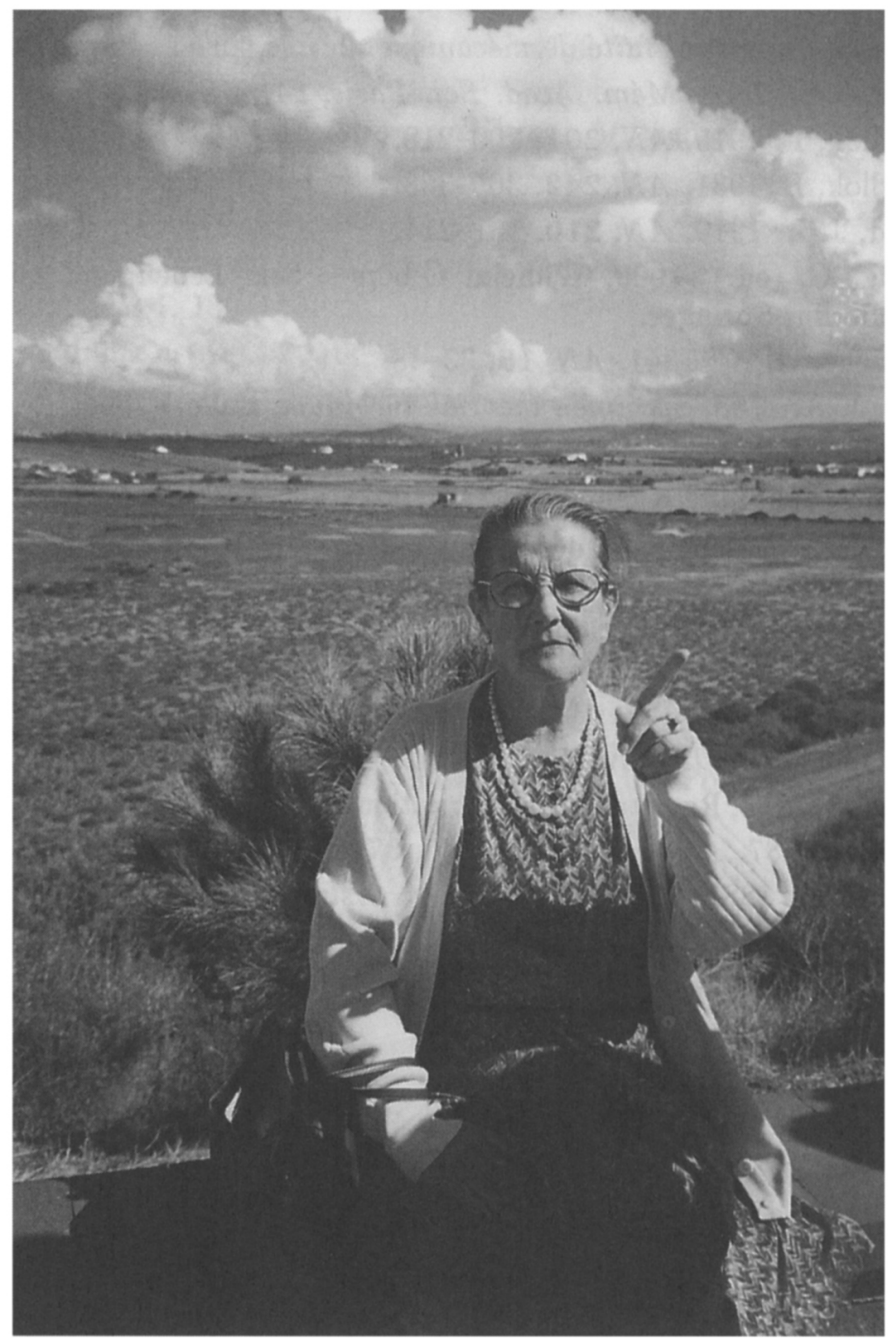

Suzanne Débarbat 